\title{
Noûs: oralidade e escrita
}

\author{
SÍLVIA MARIA FERREIRA CÚRI \\ Faculdade de Administração \\ Universidade de Santo Amaro
}

\begin{abstract}
RESUMO: Este artigo, em seus dois momentos, aborda o conceito de noûs no pensamento mítico de Homero, considerado tradição oral, e no pensamento filosófico de Anaxágoras, apresentado como tradição escrita. Não se prende, porém, à questão da oralidade e da escrita em si mesmas, preocupando-se apenas com a questão da conceituação de noûs em ambos os pensamentos, em seus contextos. Nosso objetivo foi resgatar essa palavra originariamente, analisando passagens dos poemas homéricos e dos fragmentos de Anaxágoras em que ela aparece e fazendo, para isso, uma comparação de diferentes traduções desses autores e também de léxicos especializados.
\end{abstract}

PALAVRAS-CHAVE: Pensamento; inteligência; juizo; racionalidade.

Sabemos que pensamento mítico e pensamento filosófico têm estruturas muito diferentes, ambas racionais, não supondo mútua exclusão de forma radical, como se fossem contraditórios. O mito está presente na Grécia o tempo todo, independentemente das épocas históricas em que dividimos essa cultura. Dessa forma, não é válido pensar que o pensamento mítico foi descartado pelo aparecimento do pensamento filosófico. O acontecimento extremamente importante que foi, na Grécia, o aparecimento da pólis, com mudanças políticas, sociais, psicológicas e na forma de ler a phýsis, ocasiona novo modo de pensar que desemboca na filosofia, privilégio de um grupo reduzido de homens que trabalha um tipo de saber pouco compreendido pela maioria.

Numa sociedade em que a escrita está ausente, o aedo, ao narrar os mýthoi, memoriza e improvisa, canta o que já ouviu antes e, ao mesmo tempo, é novo. Se, por um lado, conserva a tradição que se transmite, através dos bardos, de geração a geração, por outro, inova, cria em forma própria o já sabido, desenvolvendo-o e modificando-o em parte. A matéria-prima com que trabalha é composta dos acontecimentos trazidos pela tradição oral de inúmeras gerações de cantores que o antecederam. Seus mýthoi não são considerados fantasias individuais ou fabulação romanesca e livre. Têm em si um "saber": o que o aedo fala é a verdade, é o real, o acontecido, por ele não presenciado, mas "visto" e "conhecido" por inspiração das Musas. O aedo detém um "saber" mântico, uma onisciência de caráter adivinhatório que lhe credita a expressão da palavra-verdade (Detienne, 1981, p. 17). Essa palavra-verdade, de inspiração divina, sem argumentação, pois que indiscutível, tem força e 
eficácia, está intimamente ligada à ação, exige receptividade, é imagética e concreta, impondo-se de imediato cheia de sentido.

Com o advento da pólis, a palavra-diálogo, instrumento político por excelência, passa a ter a primazia dentro do pensamento lógico, fundamentado no arrazoamento, num processo de busca e investigação que exige atividade para provar sua verdade. Então, pensamento mítico, pré-lógico, e pensamento filosófico, lógico, convivem na Grécia, embora ofereçam explicações diferentes da phýsis: de um lado, a apreensão direta e emocional da ação de deuses; de outro, a busca da arkhé, do fundamento abstrato de tudo o que existe. Dessa forma, concordamos com as palavras de Guthrie', quando afirma que "... os antigos gregos, e só eles dentre os povos europeus, souberam fazer incidir a Razão sobre a sua herança religiosa e mitológica, transformando-a, numa transição suave e sem quebra, em filosofia, ou seja, numa forma racional e não mítica de encarar o mundo".

Sendo assim, o objetivo deste nosso estudo foi, primeiramente, buscar o sentido originário de noûs em Homero, tentando cercar-lhe o sentido com a fidelidade possível que a Filologia permite e, depois, analisar os fragmentos de Anáxagoras, para verificar uma possível manutenção da significação básica ou possíveis mudanças, ou, ainda, evolução do conceito da tradição oral para a tradição escrita.

Para isso, propusemo-nos a buscar uma tradução linear², mais próxima da raiz grega, sacrificando estilo e forma em favor de uma significação mais precisa, na análise de passagens homéricas e de fragmentos de Anaxágoras.

Num primeiro momento deste nosso estudo, lembrando que entender o significado de palavras pertencentes a uma cultura específica distanciada no tempo não é fácil, voltamonos para a linguagem homérica. Pudemos, então, observar que ela é concreta, imagética; suas palavras, destituídas de significações genéricas, são empregadas em sentidos específicos. Num contexto em que não existe a noção do homem como um todo corpóreo ou espiritual, ao pretender expressar o que hoje entendemos como aspectos constituintes da psiquê humana (sensação, percepção, sentimento, vontade, emoção, paixão, pensamento), Homero apresenta vocabulário variado e noûs faz parte desse vocabulário (e também phrén, thymós, kardía, khér...). Além disso, o poeta trata físico e psíquico de tal forma entrelaçados que não chega a fazer separação entre o orgânico e sua "expressão corpórea".

Um aspecto importante foi preciso considerar: as traduções existentes da llíada e da Odisséia, oferecendo inúmeros sentidos a uma mesma palavra e sentidos comuns a palavras que expressam coisas diferentes, não auxiliam no entendimento dos vocábulos no contexto da obra. Como exemplo, tomamos Cunliffe (Cunliffe, s/d, s.v. noûs, phrén, thymós) em seu vocabulário homérico, num quadro comparativo: 


\begin{tabular}{|c|c|c|}
\hline NOÛS & PHRÉN & THYMÓS \\
\hline $\begin{array}{l}\text { Mente. } \\
\text { Poder mental, inteligência; } \\
\text { bom-senso. } \\
\text { Espirito. } \\
\text { Natureza, disposição. } \\
\text { Vontade. } \\
\text { Propósito, desígnio, intento; } \\
\text { Plano, método de ação; } \\
\text { conselho. } \\
\text { Expectativa, esperança. } \\
\text { Desejo. } \\
\text { Conteúdo de conhecimento. }\end{array}$ & $\begin{array}{l}\text { Diafragma. } \\
\text { Sede: étor, thymós, khér, kradíe e noûs. } \\
\text { Coração, peito, alma, } \\
\text { Mente como a sede ou uma sede de: } \\
\text { vida, força, vitalidade; } \\
\text { inteligência, como faculdade de perce- } \\
\text { ber, conhecer, pensar, deliberar, julgar, } \\
\text { considerar, inventar; } \\
\text { como memória; } \\
\text { espirito, coragem, resolução, } \\
\text { determinação, paciência; } \\
\text { - raiva, ira, paixão; } \\
\text { - desejo, apetite, impulso sexual; } \\
\text { - vontade; } \\
\text { - sentimentos, emoções, humores; } \\
\text { - caráter, disposição; } \\
\text { - sono. } \\
\text { Interioridade. }\end{array}$ & $\begin{array}{l}\text { Coração, peito, alma, mente como sede de: } \\
\text { vida, vitalidade, força, espírito vital; } \\
\text { espírito, coragem, determinação, } \\
\text { resolução, paciência; raiva, ira, } \\
\text { indignação, } \\
\text { loucura, fúria; } \\
\text { - desejo, apetite, impulso sexual; } \\
\text { - vontade; } \\
\text { - sentimentos, emoções, humores; } \\
\text { - faculdade de percepção } \\
\text { ou conhecimento; } \\
\text { - faculdade: pensar, deliberar, julgar, } \\
\text { considerar, inventar, conjecturar; } \\
\text {-memória; } \\
\text { - caráter ou disposição. } \\
\text { Sede de khér. } \\
\text { Interioridade. }\end{array}$ \\
\hline
\end{tabular}

Numa rápida análise, pudemos constatar a sobreposição das funções ou significações de noûs, phrén e thymós. Assim, exemplificando, as três palavras - noûs, phrén e thymós - podem ser vontade, ou espírito, ou desejo, indistintamente, como mostra o quadro acima. O próprio Cunliffe afirma que, quando thymós e phrén aparecem associados, dificilmente pode ser feita distinção entre eles. Na maior parte das vezes, assim procedendo, os lingüistas resolvem o problema da língua, mas em detrimento da significação homérica. Essa dificuldade de tradução parece estar ligada à dificuldade que a própria filosofia teve quando, utilizando-se do significado mítico de noûs, quis pensá-lo abstratamente.

Tentando, então, resgatar a significação originária da palavra noûs, vimos que, segundo Chantraine (1984, s.v. noûs), ela não tem etimologia conhecida, mas algumas ligações são supostas: radical nof que o aproxima do gótico snutrs, com o significado de sábio, inteligente; neúo que é fazer um sinal pleno de sentido com a cabeça; néo que significa nadar; admite, ainda, relação engenhosa, mas incerta com antroponímicos de raiz néomai, que significa salvar. Diante de tantas suposições, Von Fritz (1943, p.93) afirma que, das muitas etimologias propostas, apenas duas merecem consideração. A primeira, de Prellwitz, que aponta o verbo neueîn (assentir com a cabeça) como derivado da mesma raiz do substantivo nóos. Este substantivo teria desenvolvido novos significados, surgindo, assim, a necessidade da criação de um novo verbo que os cobrisse. Teria aparecido noeîn. Para Von Fritz, entretanto, apesar de coerente, essa etimologia não parece provável.

A segunda proposta analisada por esse estudioso é a de Schwyzer que defende a origem de noûs na raiz $s n u^{3}$, de snófos (farejar) ${ }^{4}$. Uma objeção a essa proposta seria que, em Homero, noeîn aparece mais freqüentemente ligado ao sentido da visão que aos outros sentidos, como afirma Von Fritz, fundamentado em Snell e Krause (Von Fritz, 1943, p.88). Considerando que o sentido mais original de noeîn é "perceber e compreender uma situação" e supondo ter sido primariamente importante para o homem perceber situações que envolviam perigo, Von Fritz pensa que o sentido mais primitivo de noeîn possa ser "sentir o perigo", farejá-lo.

Ora, diz esse estudioso, nos primórdios da humanidade, o olfato desempenhou papel preponderante em relação à sobrevivência e, mesmo depois que a civilização tornou o sentido da visão mais expressivo, ainda assim o entendimento de uma situação não estava 
restrito a este último. É plausível pensar que um novo conceito, relacionado a uma função puramente mental, teve momento adequado para aparecer, cada vez mais se distanciando de uma ligação com o olfato, até que essa ligação ficasse completamente esquecida. O substantivo noûs teria sobrevivido e teria sido criado um verbo derivado dele. Para Von Fritz, essa é a etimologia mais provável.

Outra interpretação, a de Gordon Frame (Frame, 1971, p.35), propõe sua derivação da raiz indo-européia nes, a qual é encontrada no alemão com o significado primitivo de "retorno à vida", ainda perceptível na palavra moderna genesen; no sânscrito, no nome Nâsatyâ que era dado aos deuses que operavam um "retorno à vida" a mortais privilegiados, os quais "retornavam à luz"; no escandinavo noera, "revive". Na língua grega, essa raiz nes conota "retorno da morte", "retorno à luz", o que explicaria, segundo esse estudioso, por que o verbo noeîn está ligado ao sentido da visão. O significado da raiz nes parece ter tido também, já no indo-europeu, uma conotação "mental", como sugere ganisan, palavra gótica de raiz nes, com o sentido de "retorno à consciência". Essa dualidade teria levado à distribuição do significado entre ménos (alma, princípio de vida) e nóos; ménos passou a referir-se ao físico e nóos ao mental. Para Gordon Frame, isso explicaria porque, posteriormente, nóos veio a significar mente, e dessa forma já está em Homero.

Von Fritz (1943, p.80) lembra que na visão de Joachim Boehme, explicitada em obra publicada em 1929, a palavra noûs tem três principais significados: "Seele als Träger seelischer Erlebnisse" que Von Fritz traduz por alma como um órgão de experiências; "Verstand" que pode ser mente, ou intelecto, ou inteligência, ou entendimento; e "Plan" que é plano ou planejar. Explicando esses três significados de Boehme, Snell, também citado por Von Fritz (1943, p.83) diz que, então, teríamos um órgão, sua função enquanto tal e sua função num momento determinado, respectivamente. Von Fritz lembra que não é possível encontrar em Homero distinções abstratas desse tipo, mas que, se o poeta tivesse feito colocação semelhante, provavelmente noûs seria prevalentemente uma função e não um órgão.

Como a palavra noûs não tem um termo equivalente nas demais línguas, pareceu-nos mais adequado, em nosso estudo, analisá-la numa tradução linear que realizamos de várias passagens homéricas em que ela aparece, para resgatar, posteriormente, o seu significado de forma mais contextual. Vejamos, a título de ilustração, algumas dessas passagens.

Na Ilíada IX, 104, ao censurar Agamêmnon pela ofensa a Aquiles, Nestor diz:

“... pois nenhum outro noései (pensará) um noón (pensamento, juízo) melhor que este que ego noéo (eu penso, discirno agora)...

Na Odisséia V, 22, quando Atena relembra a situação de Ulisses na ilha de Calipso, Zeus responde:

"Filha minha, que palavra escapou do recinto dos teus dentes? Não é teu este noón (pensamento) por deliberação própria..."

Ainda na Ilíada XII, 255, Homero diz que, no desejo de favorecer Heitor nos combates, Zeus 
“... amoleceu o noón (juízo, pensamento) dos aqueus e aos troianos e a Heitor ofereceu a glória”.

Finalmente, na Ilíada XV, 128, apesar da proibição de Zeus, Ares decide interferir nos combates e enfrentar o Cronida, sendo impedido por Athena, que lhe diz:

“... tens ouvidos para ouvir, mas teu nóos (inteligência, discernimento) se perdeu..."

Nossa conclusão a respeito da significação de noûs em Homero é, pois, fruto de um estudo comparativo de várias traduções do poeta, inclusive a nossa e da consulta de conceituados vocabulários do grego antigo. Pensamos, assim, que o noûs homérico aparece como potência humana relacionada com a inteligência, a sagacidade, o discernimento, o juízo e a reflexão. Noûs é pensamento enquanto carregado de tais capacidades.

Num segundo momento deste nosso estudo, reportamo-nos a Anaxágoras de Clazômena (499-428/séc.V a.C.), que, dentre os filósofos pré-socráticos, foi o primeiro a abordar o noûs destituído de toda e qualquer representação. Na sua concepção cosmológica, nada é criado, nada é destruído, o todo é completo e sempre igual a si mesmo. Suas afirmações mais conhecidas são: "...homoû pánta khrémata ên..." ("no mesmo lugar estavam todas as coisas...”) (Simplício, fr. 1, citado por Kirk, Raven \& Schofield, 1987, p. 500)“, “...allà pánta pantós moîran..." (“...todas têm uma porção de tudo...”) (Simplício fr. 11, citado por Kirk, Raven \& Schofield, 1987, p. 511). Então, numa porção mínima que seja de matéria, temos os mesmos elementos universais. Anaxágoras estabelece um princípio originário que se particulariza em todas as coisas, a famosa mescla originária, em que não encontramos qualidades separadas, mas apenas mistura suposta em todas as oposições qualitativas que existem. Essa mistura originária, em que tudo está indiferenciado e nada pode ser discernido, sofre a ação de uma bía (força) e entra em processo de separação. Dessa diferenciação primeira surgem os spérmata (sementes), ou homoiomerías (partes semelhantes) segundo designação de Aristóteles, as quais são eternas, imutáveis, idênticas a si mesmas e que, por separações e diferenciações sucessivas dão origem ao cosmos. Essa força é krátos (poder) inteligente apartado da mescla primitiva, isto é, mémeiktai oúdenì khrémati (misturado a nenhuma coisa); é ápeiron (ilimitada), é autokratès (autônoma), é mónos autòs eph'eautoû (em si mesma); é leptótaton (a mais sutil) e katharótaton (a mais pura) de todas as coisas; é ós aeí estì (eterna); é de pâs homoiós estì (sempre semelhante); pánton noûs kratêิ (tudo governa); põe a mescla em movimento, symmísgethai (compõe) e diakrínetai (dissocia). Com isso faz surgir o mundo diferenciado e ordenado. Chamado noûs por Anaxágoras, esse krátos (poder) gnómen ge perì pantós (tem o conhecimento de todas as coisas); não se misturando com nenhuma coisa, rege ósa ge psykhèn ékhei (as coisas que têm alma). Imprime à mistura inicial um movimento rotatório que se expande, amplia-se com muita rapidez e violência, separando os opostos, fazendo com que as coisas surjam . O cosmos é exatamente isso: tudo o que estava na mescla primitiva e que se diferenciou pela interferência e acompanhamento de noûs (Simplício, fr12/14/17, citado por Kirk, Raven \& Schofield, 1987, p. 502-509) 
Jaeger (1982, p.160) afirma que o noûs de Anaxágoras é o espírito e, provavelmente, o espírito divino, embora o filósofo não tenha dito isso explicitamente. Reale (1983, p.147) fala muito claramente em inteligência divina. Bailly (s/d, s.v. noûs) traduz por o ser inteligente. Chantraine (1984, s.v. noûs), por inteligência suprema. Stephen Menn (1995, p.26) afirma categoricamente que o noûs é Razão, no sentido de racionalidade. Kirk, Raven e Schofield (1987, p. 507) traduzem por Mente, "uma força motriz intelectual corpórea extremamente sutil". Autores ingleses como Barnes, Guthrie e outros traduzem por mind que, de forma geral, é mente, mas também pode ter o sentido de intelecto, inteligência e racionalidade.

Analisando os vários fragmentos do filósofo, percebemos que, não admitindo geração e corrupção e diante da multiplicidade e do movimento existentes no mundo, ele faz importante e inovadora colocação, apontando noûs como uma causa independente de tudo, responsável pela ordem no mundo. As qualidades que lhe oferece são abstratas: ordena, governa, conhece, move... Isso pode levar-nos à idéia de incorporeidade, de imaterialidade de noûs. Entretanto, o filósofo não explicita esse ponto suficientemente, para que possamos chegar a essa conclusão, embora apresente noûs totalmente destituído de imagem, fruto de pensamento arrazoado. A partir do movimento inicial, não sabemos como e se noûs atua. A queixa de Platão, no Fédon 98, parece pertinente, quando diz que Anaxágoras não fez uso de noûs, apontando-o como causa real da ordem das coisas, caindo no mecanicismo físico. Aristóteles (Aristotle, 1995, p. 22) afirma que Anaxágoras identificou noûs e psykhé, mas isso não aparece nos fragmentos, muito pelo contrário, visto que o filósofo de Clazômena fala que noûs não se mistura com nada, mas está presente em algumas coisas, ósa ge psykhèn ékhei (coisas que têm alma) (Simplício, fr 12, citado por Kirk, Raven \& Schofield, 1987, p. 507). Mas está presente na alma ou no corpo animado? Não creio que possamos saber. De qualquer forma, não temos indícios de que Anaxágoras faça uso da causalidade de noûs na alma.

Concordamos com Bréhier (1988, p. 75): o noûs de Anaxágoras é inteligência, sem qualquer qualificação. Então, de certa forma, a significação homérica é mantida, levando-se em conta, evidentemente, a perda da concretude e o ganho da forma mais abstrata possível, isto é, noûs colocado como ousía e como arkhé, completamente desvinculado de qualquer qualidade humana. Além disso, pensamos que o filósofo não possui o conceito do imaterial e do espiritual, o que torna muito difícil aceitar a colocação de noûs como inteligência ou espírito divino, como pretendem alguns estudiosos. Mas, mesmo admitindo essa conceituação, estaremos admitindo uma concepção teísta não mais no terreno da tradição mítica, mas fruto de pensamento refletido, lógico.

Concluindo, podemos dizer que, apesar de tentarmos explicitar noûs da forma mais clara possível, sentimos que nos faltam palavras para fazê-lo. Usamos expressões variadas como força, princípio, poder, causa, inteligência, etc., mas somos obrigados a admitir que para coisas tão divinas o lógos é insuficiente. Apesar de o pensamento filosófico, com seu caráter especulativo e impessoal, permitir distanciamento, favorecendo o conceptual e o abstrato, ainda assim requer interpretação, o que muitas vezes esbarra no limite do lógos e, então, busca saída em expressões metafóricas do discurso, como faz muitas vezes Platão em seus diálogos. Assumindo esse limite, resta-nos apenas afirmar que o noûs da tradição oral, 
representada por Homero, e o noûs da tradição escrita, representada por Anaxágoras, têm basicamente o mesmo sentido, apesar do grande distanciamento em termos de abstração.

\section{Notas}

1 - Ver o "Prefácio à edição portuguesa" da obra de Cornford (1989), traduzida por M. M. R. Santos.

2 - As traduções das passagens homéricas foram feitas em conjunto com o Prof. Dr. Henrique Graciano Murachco, do Departamento de Letras Clássicas da USP.

3 - Chantraine (obra citada) relata que Schwyzer vê uma relação de nóos com o gótico snutrs, que significa sábio, inteligente.

4 - Entretanto, Henrique Murachco lembra que sigma antes de consoante não tende a cair. Para ele, noûs tem a mesma raiz de gignosko, relacionando-se, dessa forma, com a compreensão.

\section{Referências bibliográficas}

ARISTOTLE. On the soul. Translation of W. S. Hett. Cambridge: The Loeb Classical Library, Harvard University Press, 1995.

BAILLY, A. Dictionnaire Grec-Français. Paris: Hachette, s/d.

BRÉHIER, E. Historia de la Filosofía, vol. 1. Traducción de Juan Antonio Pérez Millán y Maria Dolores Morán. Madrid: Tecnos, 1988.

CHANTRAINE, P. Dictionnaire Étymologique de la Langue Grecque. Paris: Klincksieck, 1984.

CORNFORD, F. M. Principium Sapientiae. As origens do pensamento filosófico grego. Tradução de Maria Manuela Rocheta dos Santos. Lisboa: Calouste Gulbenkian, 1989.

CUNLIFFE, R.J. A Lexicon of the Homeric Dialect. Norman: University of Oklahoma Press, s/d.

DETIENNE, M. Os mestres da Verdade na Grécia Arcaica. Tradução de Andréa Daher. Rio: Zahar, 1981.

FRAME, D. G. The origins of Greek noûs (Tese de doutorado). Harvard University. Cambridge, 1971.

HOMER. The Iliad. Translation M. Hammond. London: Penguin Books, 1987.

The Odissey. Translation E.V. Riew. London: Penguin Books, 1991.

Iliad. \& Odissey - 2 vol. Translation A. T. Murray. Cambridge: The Loeb Classical Library, Harvard University Press, 1995.

HOMÈRE. Iliade. Traduction P. Mazon. Paris: Les Belles Lettres, 1937.

Odyssée. Traduction V. Bérard. Paris: Les Belles Lettres, 1946.

HOMERO. Ilíada e Odisséia. Tradução Carlos Alberto Nunes. Rio de Janeiro: Ediouro, s/d. 
JAEGER, W. La teologia de los primeros filósofos griegos. Traducción de José Gaos. Madrid: Fondo de Cultura Económica, 1982.

KIRK, G. S.\& RAVEN, J.E.\& SCHOFIELD, M. Los filósofos presocráticos.Madrid: Gredos.1987.

MENN, S. Plato on God as Noûs. Carbondale: Southern Illinois University Press, 1995.

PLATO. Timaeus. Translation of R.G. Bury. Cambridge: The Loeb Classical Library, Harvard University Press. 1995.

REALE, G. História da Filosofia Antiga. Vol. 1. Tradução de Marcelo Perine. São Paulo: Loyola, 1993.

VON FRITZ, K. "Noûs and noein in the Homeric Poems".Classical Philology 38, 1943, p. 79-93.

CURI, Sílvia Maria Ferreira. Noûs: orality and writing. Classica, São Paulo, 13/14, p. 323-330, 2000/2001.

ABSTRACT: In two moments, this article deals with the concept of noûs in Homer's mythical thought, considered as oral tradition and in Anaxagoras' philosophical thought presented as written tradition. However, it does not deal specifically with orality or writing but with the concept of noûs in the texts of both authors, in their contexts. Our aim is to recover its original meaning through the analysis of Homer's poems and Anaxagoras 'fragments where the word noûs appears. We have developed our work through the comparison of several translations of these authors and specialized lexicons.

KEYWORDS:Thought; intelligence; judgement; rationality. 